\title{
An Overview of Health Care Worker Reported Deaths During the COVID-19 Pandemic
}

\author{
Divakara Gouda, BS, Preet Mohinder Singh, MD, Prabhakara Gouda, and \\ Basavana Goudra, MD, FRCA, FCARCSI
}

Objectives: As of May 13, 2020, 1004 health care worker (HCW) deaths due to coronavirus disease 2019 (COVID-19) have been reported globally. This study seeks to organize deaths by demographic group, including age, gender, country, and occupation.

Methods: We collected data from a crowdsourced list of global HCW COVID-19 deaths published by Medscape, including age, gender, country, occupation, and physician specialty.

Results: As of May 13, 2020, of $1004 \mathrm{HCW}$ deaths, 550 were physicians. The average age of physician death is 62.49, skewed right, and nonphysician is 52.62, approximately symmetrical. The majority of U.S. HCW deaths are male (64.1\%). General practitioners and family medicine and primary care physicians account for $\mathbf{2 6 . 9 \%}$ of physician deaths. Anesthesiologists and emergency medicine and critical care physicians account for $7.4 \%$. The United States has the highest number of HCW deaths but a similar number as a fraction of national cases and deaths compared with other developed countries.

Conclusions: Among HCWs globally, in the United States there have been more reported deaths of physicians, primary care physicians, males, and HCWs versus opposing groups. Further research is needed to understand relative risks of death due to COVID-19 in each of these demographic groups. (J Am Board Fam Med 2021;34:S244-S246.)

Keywords: COVID-19, Family Medicine, Primary Care Physicians, Primary Health Care, Risk

\section{Introduction}

Since coronavirus disease 2019 (COVID-19) has impacted the world beginning in December 2019, there has been a great deal of concern about the safety of health care workers (HCWs). Inadequate personal protection is a core issue, especially for frontline HCWs. Duration of exposure and frequency of exposure is another important risk factor. ${ }^{1}$

Analysis of HCW deaths due to COVID-19 will provide a way of identifying the scope of this

This article was externally peer reviewed.

Submitted 22 May 2020; revised 12 July 2020; accepted 15 July 2020.

From the Rowan School of Osteopathic Medicine, Stratford, NJ (DG); Department of Anesthesiology, Washington University School of Medicine in St. Louis, MO (PMS); Saint Louis University, St. Louis, MO (PG); Perelman School of Medicine, Hospital of the University of Pennsylvania, Philadelphia, PA (BG).

Funding: None.

Conflict of interest: None.

Corresponding author: Basavana Goudra, MD, FRCA, FCARCSI, Clinical Associate Professor of Anesthesiology and Critical Care Medicine. Perelman School of Medicine, Hospital of the University of Pennsylvania, 680 Dulles, 3400 Spruce Street, Philadelphia, PA 19104 (E-mail: goudrab@ uphs.upenn.edu) problem. An exploration of these deaths might assist administrators in planning safety and resource use.

\section{Methods}

We gathered data on reported HCW deaths globally from Medscape, which publishes a crowdsourced list of HCW deaths from its readers. Medscape requires a confirmation of death for all submissions. The list contains some or all demographic data on age, country of death, and occupation. We inferred gender of United States HCWs based on first name. We subdivided occupation into physician and nonphysician and further subdivided physicians into specialties.

\section{Results and Discussion}

As of May 13, 2020, a total of 1004 HCW deaths have been reported globally by Medscape. More than half of the HCWs were physicians (54.8\%). Nonphysicians in our study included nurses, nursing assistants, physician assistants, paramedics, technicians, patient transporters, social workers, pharmacists, epidemiologists, and administrative staff. 
Table 1. Specialty of Physician Deaths, as of May 13, 2020

\begin{tabular}{|c|c|c|}
\hline Specialty of Physician Deaths & Number & Percent \\
\hline Anesthesiology & 15 & 2.7 \\
\hline Cardiology & 21 & 3.8 \\
\hline Dermatology & 4 & 0.7 \\
\hline Emergency medicine/critical care & 26 & 4.7 \\
\hline Endocrinology & 2 & 0.4 \\
\hline Ear, nose, and throat & 8 & 1.5 \\
\hline Gastroenterology & 1 & 0.2 \\
\hline $\begin{array}{l}\text { General practitioner/family medicine/ } \\
\text { primary care }\end{array}$ & 148 & 26.9 \\
\hline Geriatrics & 4 & 0.7 \\
\hline Hematology & 4 & 0.7 \\
\hline Infectious disease & 5 & 0.9 \\
\hline Internal medicine & 30 & 5.5 \\
\hline Nephrology & 6 & 1.1 \\
\hline Neurology & 6 & 1.1 \\
\hline Neurosurgery & 6 & 1.1 \\
\hline Obstetrician-gynecologist & 22 & 4.0 \\
\hline Oncology & 3 & 0.5 \\
\hline Ophthalmology & 13 & 2.4 \\
\hline Orthopedist & 15 & 2.7 \\
\hline Otolaryngology & 6 & 1.1 \\
\hline Pathology/histopathology & 10 & 1.8 \\
\hline Pediatrics & 26 & 4.7 \\
\hline Plastic surgery & 4 & 0.7 \\
\hline Psychiatry & 11 & 2.0 \\
\hline Pulmonology & 13 & 2.4 \\
\hline Radiology & 13 & 2.4 \\
\hline Rheumatology & 1 & 0.2 \\
\hline Surgery & 33 & 6.0 \\
\hline Urology & 8 & 1.5 \\
\hline Other & 29 & 5.3 \\
\hline Total & 493 & 89.6 \\
\hline Missing & 57 & 10.4 \\
\hline Total & 550 & 100.0 \\
\hline
\end{tabular}

The mean age of physician deaths is 62.49 years and nonphysician deaths is 52.62 years. Disproportionately more physician deaths occurred in the age group above 50 years, especially 60 to 80 . This is possibly due to the skewed age distribution between physicians and nonphysicians. Of approximately 2 million registered nurses in the United States, 22\% are over the age of 55 . Similarly, 20\% of approximately 1.2 million physicians are over the age of $55 .^{2}$ This difference in average age must be accounted for in understanding this data.

In the United States, more male than female HCW deaths have been reported (132 vs 74).
This difference is consistent with other published data on gender susceptibility to COVID19. Jin et al. found that two thirds of COVID-19 patients were male and male cases tended to be more serious. ${ }^{3}$ Other studies have also addressed issues such as gender and ethnicity in relation to HCW deaths. Disproportionately more African Americans have died in the United States. In the United Kingdom, black, Asian, and minority doctors have died in disproportionately larger numbers. ${ }^{4}$

General practitioner/family medicine/primary care physicians form the largest subset of physician deaths (26.9\%, Table 1). Anesthesiologists and emergency medicine and critical care physicians, who are often frontline workers, form a smaller subset $(7.4 \%)$. A possible explanation is that they are more likely to interact with asymptomatic patients and have inadequate personal protective equipment. $^{5}$

The United States has more HCW deaths that any other country but not as a fraction of cases and total national deaths. Using these metrics, the United States is similar to other developed countries including the United Kingdom, Italy, and France. In the United States, New York and New Jersey have the highest number of HCW deaths

A limitation of this study is that the Medscape list of HCW deaths is a convenience sample and likely to be incomplete, as it is crowdsourced from its readers. There are likely more than 1004 HCW deaths globally. Reporting of deaths also varies from country to country. Physicians, for example, may have more access to testing and treatment and as a result be overrepresented compared with nonphysicians. At least 2 reported deaths were suicides. Although the issues of workrelated stress and burnout among HCWs should not be understated, this is another factor that may skew our data.

To see this article online, please go to: http://jabfm.org/content/ 34/Supplement/S244.full.

\section{References}

1. Wang J, Zhou M, Liu F. Reasons for healthcare workers becoming infected with novel coronavirus disease 2019 (COVID-19) in China. J Hosp Infect 2020;105:100-1.

2. Ehrlich H, McKenney M, Elkbuli A. Protecting our healthcare workers during the COVID-19 pandemic. Am J Emerg Med 2020;38:1527-8. 
3. Jin J-M, Bai P, He W, et al. Gender differences in patients with COVID-19: focus on severity and mortality. Frontiers in Public Health. 2020. Available from: https://www.frontiersin.org/articles/10.3389/ fpubh.2020.00152/full. Accessed May 15, 2020.

4. Patterson C. BAME doctors hit worse by lack of PPE. British Medical Association. 2020. Available from: https://www.bma.org.uk/news-and-opinion/ bame-doctors-hit-worse-by-lack-of-ppe. Accessed May 16, 2020.

5. Primary Care Collaborative. Primary care \& COVID19: week 1 survey. 2020. Available from: https://www. pcpcc.org/2020/03/19/primary-care-covid-19-week1-survey. Accessed May 17, 2020. 